\title{
SMART PUBLIC DISTRIBUTION SYSTEM
}

\author{
${ }^{1}$ Rajesh P.Deshmukh and Pravin W. Raut \\ Associate Professor, Department of Electronics and Telecommunication Engineering \\ Yeshwantrao Chavan College of Engineering, Nagpur, India \\ Email: \{1rpd.ycce@gmail.com, pravinwraut@hotmail.com\}
}

\begin{abstract}
Ration card is an important government document used for the purchase of subsidized food grains by most of the households in India. But this system has two major drawbacks A) Inaccurate quantity measurement of food grains caused by human errors or by intentional use of inaccurate weights. B) High probability of fraudulent sale in the market in case of partial consumption of food grains allotted every month. To make the process more streamline and transparent, a Smart Card Based Public Distribution System using RFID (Radio Frequency Identification) technology is proposed.
\end{abstract}

Keywords: RFID:EM 18 RF Reader Module, Arduino UNO, ATMEGA328P

\section{Introduction}

Public distribution system (PDS) is a government based network of fair priced shops intended to distribute essential food and non-food items to poor section of society. Through PDS majorly staple food grains such as rice, sugar, wheat and essential fuels are distributed on large scale. Ration card is an official government issued document to eligible households for the purchase of subsidized essential goods. However, there are certain loopholes that are taken undue advantage of by fraudsters leading to high corruption. Two major drawbacks in the current system are:

A) Inaccurate quantity measurement caused by human errors or by intentional use of inaccurate weights

B) Fraudulent sale in the black market in case of partial consumption of food grains allotted every month.

In this paper, we propose a concept on automatic distribution of ration products using RFID technology to compensate for the major drawbacks of existing PDS and prevent corruption. Smart Public Distribution System uses a Smart Card based of RFID technology instead of existing Ration Card. Smart. Each card is mapped to a unique number, details of household, family head photo ID and mobile number through the database. Once the smart card is swiped, the user needs to enter the type of item to be procured and also the quantity. The servo motor based system allows accurate dispensation of specified item according to the quantity specified. After the transactions, available quota of each item for the month is updated automatically in the back end database. To maintain transparency, recorded transaction details are text messaged on the registered mobile number associated with the smart card. To assure security, back end database is not accessible to the shopkeepers at ration shops.

Main aim of this system is accurate distribution of items according to specified quantity by user. Servo Motor based dispensation writes off any chance of intentional use of inaccurate weights. Real time data is updated in the back end database which helps to track overall quantity of each item and prevents black marketing. Automatic system generated text message on the registered mobile number helps the consumer to keep track of the monthly ration budgets and also keeps the system transparent.

\section{Material and Method}

To get rid of the drawbacks of existing ration system the Smart Public Distribution System is useful. Smart card with RFID technology acts as ration card. To procure items from ration shops user needs to scan the RFID tag into the RFID reader, then the controller checks customer attributes and details from the back end database. After verification, customer needs to enter the required items and quantity by using keypad. After receiving the input controller triggers the automatic dispensation system and accurate quantity of item is dispensed to the customer. The amount is transacted from the linked bank account. After the transaction backend database is updated.

\section{A) RFID : EM 18 RF Reader Module}

RFID (Radio Frequency Identification) is one of the methods for identification unique attributes using radio waves. The RFID system mainly consists of: readers, antennas and tags which can carry the data on a single microchip. Nowadays, RFID technology is used in many fields, including security and access controlling, transportation and supply chain tracking etc. Bar Code scanners are popular means of inventory tracking. However, RFID has additional benefits. RFID has longer reading range than barcode, does not require employee at shop to be within line of sight of the item, and it also mitigates the risk of theft and frauds.

Information collected from the tags is transferred through a communications interface to a host computer system where attributes checked. Here, EM 18 RF Reader Module is used. It has Operating voltage of $+4.5 \mathrm{~V}$ to $+5.5 \mathrm{~V}$, current consumption of $50 \mathrm{~mA}$, operating temperature of $0^{\circ} \mathrm{C}$ to $+80^{\circ} \mathrm{C}$, operating frequency of $125 \mathrm{KHz}$ and communication parameter of 9600 bps.

\section{B) ARDUINO UNO}

The micro-controller used here is ATMEGA328P. Arduino is an open source computing platform, flexibly designed with the help of micro-controller and software development environments. The Arduino integrated development environment (IDE) is a cross platform application written in Java and most of the programs are written in high level language. It can run on all operating systems like Windows, Mac OS and Linux. It has 20 input/output pins, $16 \mathrm{MHz}$ resonator, a power jack, USB connection, ICSP. 


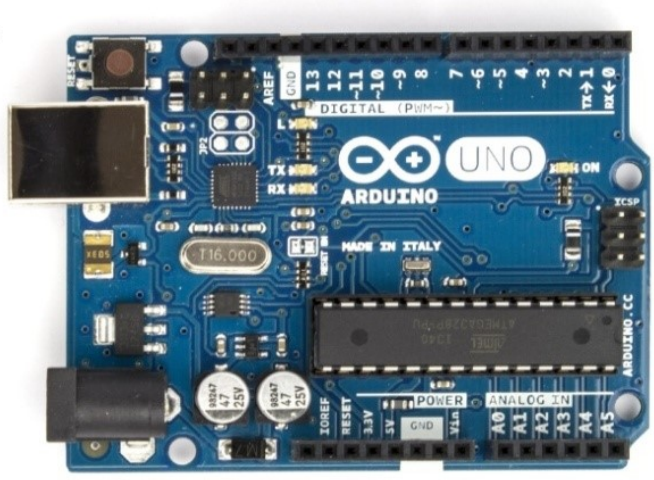

Fig 1: ARDUINO UNO

\section{ATMega328P and Arduino Uno Pin Mapping}

\begin{tabular}{|c|c|c|c|}
\hline \multirow{2}{*}{$\begin{array}{l}\text { Arduino function } \\
\text { reset }\end{array}$} & & & Arduino function \\
\hline & (PCINT 14/RESET) PC6 & PC5 (ADC5/SCL/PCINT13) & analog input 5 \\
\hline digital pin 0 (RX) & (PCINT16/RXD) PDoC 2 & ${ }_{27} \mathrm{PC} 4$ (ADC4/SDA/PCINT12) & analog input 4 \\
\hline digital pin $1(T X)$ & (PCINT17 $\pi$ XD) PD1 ${ }_{3}$ & ${ }^{26} \mathrm{PPC3}$ (ADC3/PCINT11) & analog input 3 \\
\hline digital pin 2 & (PCINT18INTO) PD2 ${ }_{4}^{4}$ & ${ }_{25} \mathrm{PPC2}$ (ADC2/PCINT 10) & analog input 2 \\
\hline digital pin 3 (PWM) & (PCINT19/OC2B/NT1) PD3 5 & ${ }_{24} \mathrm{PPC1}$ (ADC1/PCINT9) & analog input 1 \\
\hline digital pin 4 & (PCINT2O/XCKIT) PD4 6 & ${ }_{23} \mathrm{PPCO}$ (ADCOIPCINTB) & analog input 0 \\
\hline VCC & $\operatorname{vcc}$ & $20 \mathrm{GND}$ & GND \\
\hline GND & GNDC & 21. AREF & analog reference \\
\hline crystal & (PCINT6/XTAL1/TOSC1) PB6C) & 20 avcc & vCC \\
\hline crystal & (PCINT7/XTAL2/TOSC2) PB7C & 19 PB5 (SCKJPCINT5) & digital pin 13 \\
\hline digital pin 5 (PWM) & (PCINT21/OCOB/T1) PD5 " & ${ }_{18} \mathrm{~PB} 4$ (MISO/PCINT4) & digital pin 12 \\
\hline digital pin 6 (PWM) & (PCINT22/OCOA/AINO) PD6C & ${ }_{17} \mathrm{~PB} 3$ (MOSI/OC2A/PCINT3) & 3) digital pin 11(PWM) \\
\hline digital pin 7 & (PCINT23/AIN1) PD7 & 16 PB2 (SS/OC1B/PCINT2) & digital pin 10 (PWM) \\
\hline digital pin 8 & (PCINTO/CLKO/ICP1) PBOD & 15 PB1 (OC1A/PCINT1) & digital pin 9 (PWM) \\
\hline & $\begin{array}{l}\text { Digtal Pins } 11,12 \\
\text { MISO SCXocm }\end{array}$ & $\begin{array}{l}\text { ICSP header tor MOSI, } \\
\text { in } 17.188 \text { 19. Avid liow. }\end{array}$ & \\
\hline & impestance loac: & g the ICSP header. & \\
\hline
\end{tabular}

Fig 2 : ATMea328P and Arduino Uno Pin Mapping

\section{C) Power supply}

The Power Supply is most important for micro controller and all other electronic circuits. Here $12 \mathrm{~V}$ power supply is required. It consists of $230 \mathrm{~V}, 50 \mathrm{~Hz}$ step down transformer which gives 12 volt, $1 \mathrm{~A} \mathrm{AC}$ voltage. Rectifier is used in order to convert $\mathrm{AC}$ voltage to corresponding $\mathrm{DC}$ voltage. Then filters are used to remove the ripples in the output.

\section{D) Load cell}

A load cell is a weight measurement device useful for any electronic scales that display weights in digits. Load cell is a passive transducer/ sensor that converts applied force into electrical signals just like any weighting machines in grocery shops.

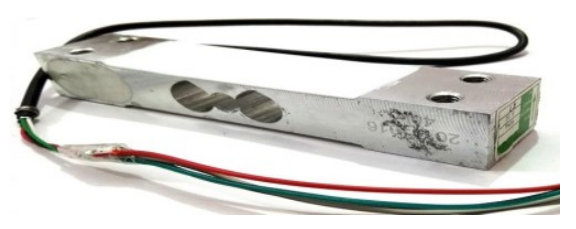

Fig 3: Load Cell

\section{E) SERVO MOTOR}

It is an electrical device which can push and rotate an object with great precision. The position of servo motor is decided by electrical pulses and its circuitry is placed inside it. For the accurate dispensation of items in specified quantities, automatic dispensation system is governed by servo motors for precision rotation and position of vessel from which items are dispensed. Servo motors used here has the rated output of $200 \mathrm{~W}$, rated torque $0.64 \mathrm{Nm}$ and peak torque of $1.91 \mathrm{Nm}$ and rated speed of $3000 \mathrm{RPM}$

\section{F) $\mathrm{METHOD}$}

First the user has to scan the RFID card by using $E M 18 R F$ Reader Module (passive) which works in the range of $125 \mathrm{Mhz}$ frequency to check whether card is valid or not. After scanning the card, if attributes are valid, screen will display the user info and various types of items on screen for selecting. This is achieved through Visual Studio. Once the customer inputs the item and quantity to be procured, the command goes to the microcontroller which triggers servo motor. Servo motor then changes its shaft as per the signal from microcontroller to drop the wanted item through vessel. The accurate quantity is sensed by the load cell at the end of circuit. As the required quantity value is attained, the load cell feeds back the signal to servo motor to stop working and hence the feedback flow is generated. The quantity is displayed on Arduino screen as an output. System generated message is sent to the registered mobile number and backend database is updated.

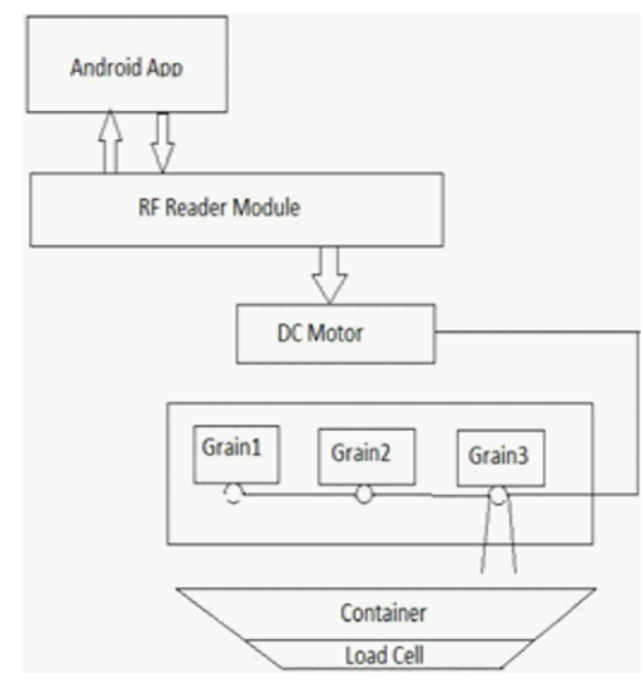

Fig 4: Block diagram 


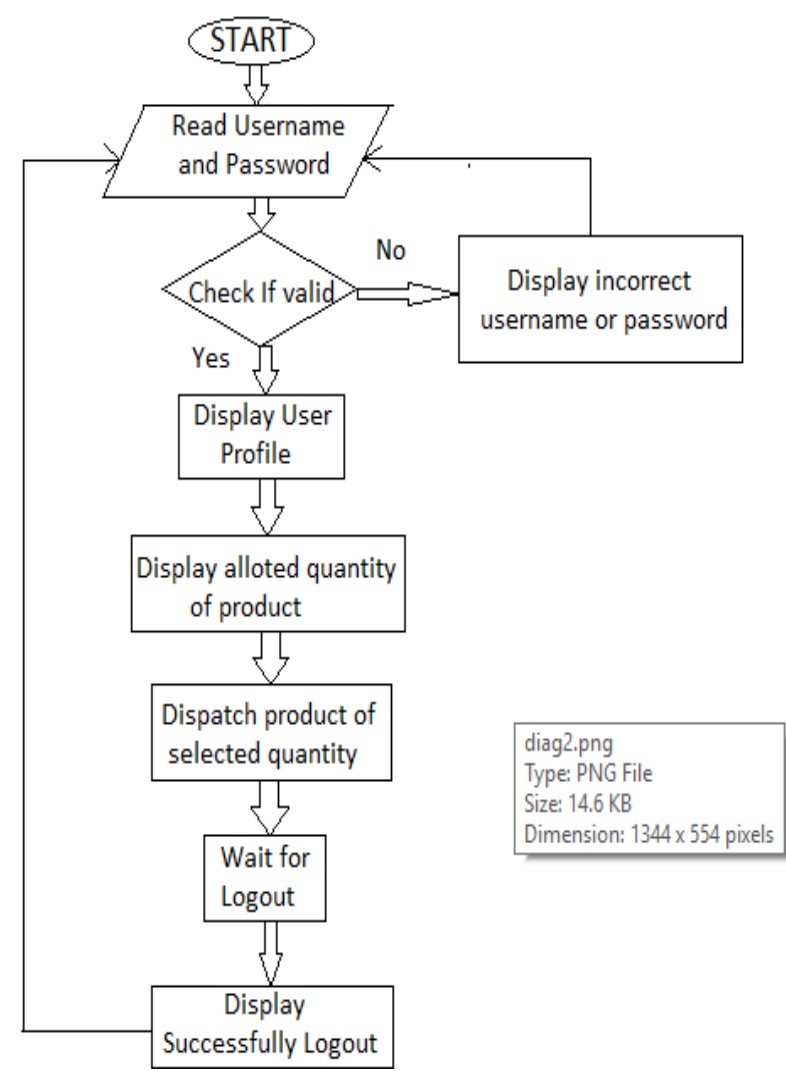

Fig 5: Flow chart

\section{Result and Discussion}

The Public Distribution System in India was first started in January 1945, during Second World War. During the Bengal Famine, to ensure distribution of essential food and non-food items to poor section of society at subsidized rates, rationing system was introduced. This rationing system was revived during acute food shortages in 1960s. Since then, there has been hardly any effective change in the system to make it efficient. India's PDS has the coverage of around 40 million below poverty line families. Numerous structural shortcomings and disturbances have been discovered in the existing system by different studies and reviews. Ration shop owners have been found to create large number of bogus ration cards to sell food grains in the open market. Intentional use of incorrect weights leads to the corruption on large scale. India's grain stock is highest in the world besides China. The government spends almost 1 percent of GDP, yet $21 \%$ remain undernourished. Hence, it is very important to make the existing system more transparent, accountable, accurate and efficient.

In the proposed smart cards are used instead of ration cards. Unique number is associated with every smart card and linked to the back end database. This ensures that no bogus cards are running in the system. Sensor based dispensation system ensures accurate distribution of items. System generated text message on the registered mobile number makes the system more transparent. Real time updating of back end database makes it more accountable and efficient.
Each account is associated with unique username and password in order to check the correct user access [1]. If the user is correct, input can then be given on the touch screen. When the products are procured from the automated ration shop, amount is debited from the bank account linked to the smart card. For the real time update, the proposed ration shop system is mapped to the government database through GSM modules [2], which further sends the up-to-date information to the government and the consumer

The smart card uses RFID technology to read the user data [3]. Using GSM, data is fed to the microcontroller [4]. Microcontroller compares the data with the database which is stored in the computer. On confirmation of credentials, user is asked to enter items to be procured and also quantity. Automatic dispensation system in then actuated by sensor, and items are dispensed through operation of valves[5].

Required items are distributed through automatic system without any manual efforts. The dispensation system governed by servo motor and load cell ensures accurate distribution of items. This system is very simple in construction and has low power consumption. Real time update of backend database and delivery of text message to registered mobile number makes the system transparent.

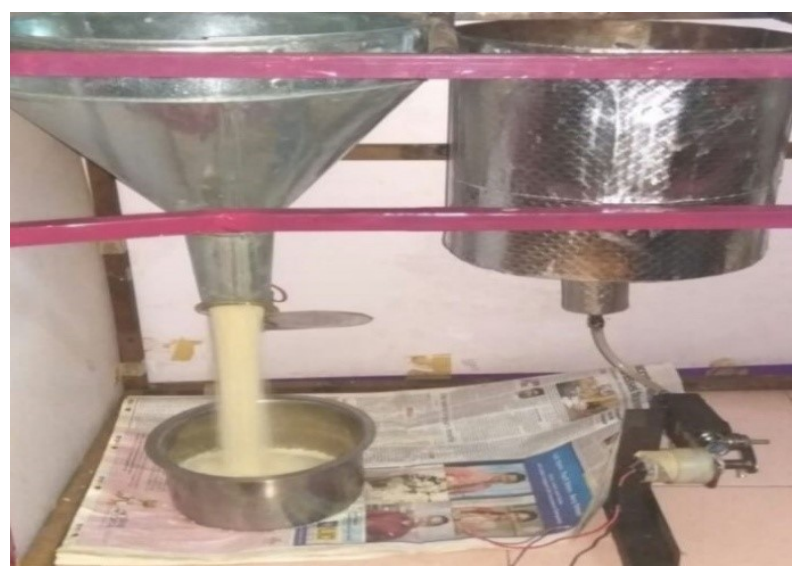

Fig 6: Dispensation through Smart PDS

\section{Conclusion}

This is a ration system based on RFID technology. The aim of the system is to automate the distribution process and make it convenient for the customers to track their quota of the month. Fully digital interface and real time update of the database makes the system very transparent and protects the interests of the public by countering the malpractices. This system has greater scope in future. This system has no manual interface and all information is stored and updated in database. Database is accessible to very limited the higher authorities those are accountable.

Servo Motor based dispensation writes off any chance of intentional use of inaccurate weights. Real time data is updated in the back end database which helps to track overall quantity of each item and prevents black marketing. 
Automatic system generated text message on the registered mobile number helps the consumer to keep track of the monthly ration budgets and also keeps the system transparent.

\section{Acknowledgement}

We would like to show our gratitude to IT Education, Nagpur for giving us a good guideline for this project through numerous consultations. We would also like to expand our deepest gratitude to all those who have directly and indirectly guided us in writing this academic research paper.

\section{References}

[1] Sana A. QaderPerampalli, Dr. R.R. Dube "Smart Card based e-Public Distribution System", International Journal of Advanced Research in Computer and Communication Engineering Volume 5, Issue 5, May 2016. ISSN (online) 2278-1021.
[2] S. Valarmathy, R. Ramani, "Automatic Ration Material distributions Based on GSM and RFID Technology", International Journal of Intelligent Systems and Applications, vol 5,pp.47-54, October 2013.

[3] Bhalekar D, Kulkarni R, Lawande K, Patil V, ”Online Ration Card System Using RFID and biometric, International Journal of Advanced Research Computer and Software Engineering(10), pp-849-81, October 2014.

[4] Smart Card Based Public Distribution System (IJSR) ISSN (online):2319-7064 Rijo PC, Chirsti Paulicen, Manoj A, Rahul M Jaya Pal, Riya Banarjee, Raisy Raphi K Shreenivas R. Jog, M.S.Sutaone ,V.V.Badawe (C2011 IEEE

[5] Automated Ration Distribution System using RFID/UID and IOT.ISSN:2278-8948 Volume 6, Issue-1-2-2017. Noor Aliba, SaumyaPrlyam, VikasPathak. 